\title{
ESPR: a new dimension for its 20th anniversary!!
}

\author{
Philippe Garrigues
}

Received: 15 March 2013 / Accepted: 24 April 2013 /Published online: 31 May 2013

(C) Springer-Verlag Berlin Heidelberg 2013

The 2013 issues will represent the 20th year of publishing Environmental Science and Pollution Research (ESPR). First of all, I would like to pay my sincerest respects to Professor Otto Hutzinger, the founding father of ESPR, who passed away in late 2012. He was really a visionary in launching ESPR, which he himself defined as "a medium of communication and information with a truly and interdisciplinary outlook" (Hutzinger 1994). Thank you, Otto, for being our guide and I hope that you would be proud of the ESPR 2013 version.

In the last 4 years, ESPR has witnessed an incredible increase in activity, moving from around 250 papers submitted in 2009 to around 2,000 papers submitted in 2012. In 2012, the format of the ESPR issues shifted from 200 printed pages to 600 printed pages, increasing both the number of issues and the speed of publication. One hundred sixty papers were accepted in 2011 and 450 papers published in 2012 . In the meantime, the time to publication acceptance has dropped to an average of 1.5 months.

Such publication growth is partly due to the journal's 2011/2012 editorial policy. ESPR has a broad scientific scope that allows various research communities (from ecology to environmental engineering, from ecotoxicology to environmental chemistry) to be active in submitting papers to the journal. Publications in new research areas such as "Sustainability", "Environmental Life Cycle Assessment", and "Green Processes" have since been accepted in ESPR. An active campaign has been made to encourage the international research community in environmental and pollution sciences to submit their works to ESPR. New publication concepts have also been introduced, such as "Special Issues" (collection of papers dedicated to specific research meetings or projects) and "Highlight Projects" (brief presentations of a research project in 2-3 printed pages). Besides these new ideas, classic topics such as research papers, paper reviews, and conference reports are always welcome.

Responsible editor: Philippe Garrigues

P. Garrigues $(\bowtie)$

Department of Molecular Sciences, University of Bordeaux 1,

Talence, France

e-mail: p.garrigues@ism.u-bordeaux1.fr
This growth in activity has also impacted the editorial organization of the journal. An editorial assistant has been recruited and is working full time in close collaboration with the Editor in Chief. The assistant serves as a liaison between the authors, the editors, and the editorial Springer Staff, ensuring a fluid and smooth formation of the ESPR issues. The number of the editors has also been significantly increased to 20 , and the number of the editorial board members is now around 50. Many thanks to the members of the two boards and to the referees for their excellent job of assessing the scientific quality of the submitted works, and for encouraging specific scientific communities to submit papers to ESPR. Special thanks are due Prof. E. Stephanou, who has since left his position of editor due to heavy university duties, for his valued contributions.

Several new editors have been selected as top level and high-impact experts in their specific disciplines and have been invited to serve for 3 years. New editors have been recruited in inorganic and organic environmental chemistry, environmental engineering, environmental microbiology, and atmosphere. You will find a short biographical sketch of each of them as follows.

Finally, I intend for ESPR to maintain its cross-disciplinary view among all the disciplines involved in the environmental sciences. More integration is needed between both disciplinary research fields and observation levels. Each article published in ESPR will contribute to achieving these objectives.

Acknowledgments I would like to acknowledge the continuous support of Paul Roos, Editorial Director for Springer's Environmental Sciences and the Heidelberg editorial staff, especially Monika Bechtold and Claudia Schiffers. I would also like to thank Emmanuelle Pignard-Péguet, for her strong involvement in the life of ESPR as an editorial assistant, and finally Walter Giger for his valued advice on the handling and the future of the journal.

\section{Reference}

Hutzinger O (1994) Editorial by Otto Hutzinger, Editor in Chief. Environ Sci Pollut Res 1(1):3 


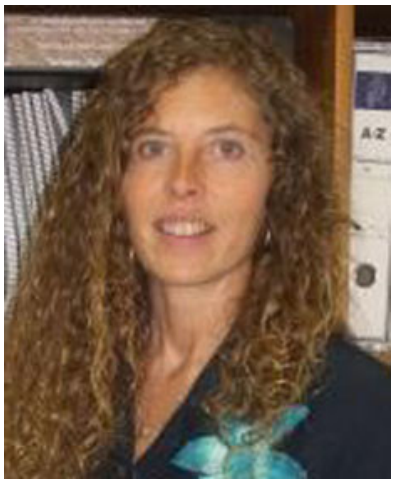

Dr. Angeles Blanco is Professor in Chemical Engineering at Complutense University of Madrid (UCM). She received the $\mathrm{PhD}$ on Chemical Engineering in April 1994. In 1991, she started to work at the Chemical Engineering Department of the UCM where she is now Professor and leader of the Cellulose and Paper Research Group.

In 1990, she founded her own company "Ecomanagement". During two years she was the Technical Manager. Since 1993 she works full time for the Complutense University. Her research areas are related to Industrial Processes and Environmental Sciences. She has participated in 17 European projects (14 as responsible) and in 49 industrial projects. She has received the "IIBCC 2008 Excellence Award in Recognition of Outstanding Research on Inorganic Bonded Composites".

She is board member of the European Water Partnership and she is collaborating in the groups of Sustainable Water Management, Water and Energy and Climate Change. She has been Vice-president of the European Fibre and Paper Research Organisations (EFPRO) during 6 years. She participated in the elaboration of the Strategic Research Agenda of the Forest-based Technology Platform (co-leader of paper value chain) and she was member of the Scientific Council and of the Education Group. She participated in the elaboration of the Vision Document and the Strategic Research Agenda of the Water Supply and Sanitation Technology Platform (WSSTP). She has been the COST Spanish representative for the Forestry Products Domain for 15 years. She is member of the Research Committee of TAPPI (Association of the worldwide pulp, paper, packaging and converting industries).

Competences : environmental engineering \& science, water treatments, chemical engineering, industrial processes, FBRM, PVM, organic $\&$ inorganic pollutants, water and waste water, sustainable processes, paper recycling.

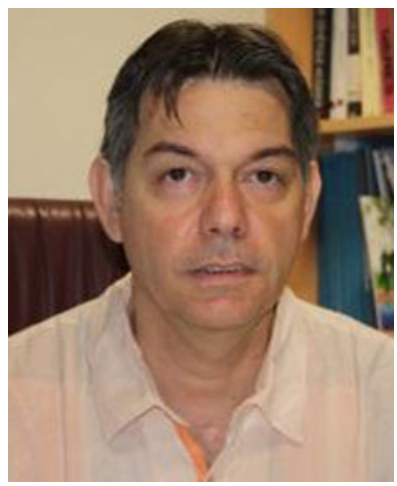

Dr. Robert Duran is Professor in Environmental Molecular Microbiology at the University of Pau. Robert has more than 20 years' experience in environmental microbiology and molecular microbiology research. He is leading a research team of 30 people including people with permanent position (professors and assistant professors, technicians), post-docs and $\mathrm{PhD}$ students. His research focuses on microbial ecology and diversity, with an emphasis on extreme, polluted or estuarine ecosystems. He employs a wide-range of techniques (from geochemistry to metatranscriptomics) to address fundamental and practical issues. Relevant recent discoveries include the characterization of the taxonomic and functional microbialdiversity in extreme and contaminated ecosystems: behaviour of sulfate reducing bacteria populations in acid mine drainage and microbial mats according to the fluctuation of environmental parameters, the diversity of ring hydroxylating dioxygenases in polluted microbial mats.

Competences : microbiology, microbial ecology, molecular biology, meta 'omics', organic compounds, metals, marine and fresh waters.

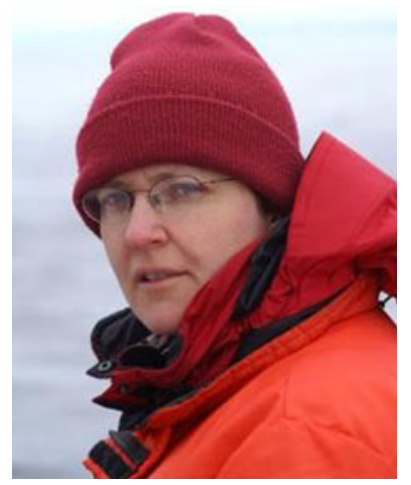

Dr. Céline Guéguen Canada Research Chair in Aquatic Sciences and Biogeochemistry, is an associate professor in the department of chemistry at Trent University. As biogeochemist and chemical oceanographer, her work focuses on the processes regulating the transport and bioavailability of metals in aquatic ecosystems. In particular, she is interested in the characterization of aquatic dissolved organic matter (DOM) in terrestrial and marine waters as well as the impacts of biogeochemical transformation of DOM on metal speciation and toxicity.

Competences : aquatic chemistry, biogeochemistry, polar chemistry, heavy metals, dissolved organic matter, humic substances, natural colloids, biodegradation, photodegradation, complexation, dissociation, partitioning.

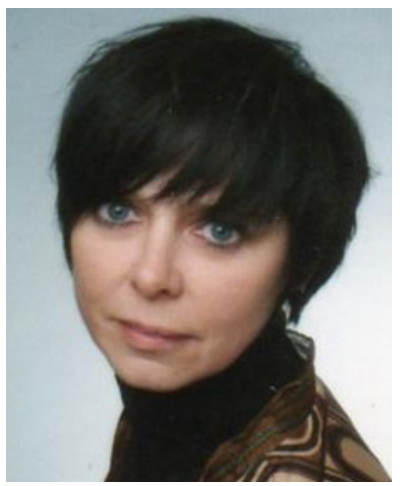

Dr. Ester Heath studied Chemistry at Faculty of Natural Sciences, University of Ljubljana, Slovenia. She has been employed at Jožef Stefan Institute in Ljubljana, Slovenia since 1991. She carried out the experimental part of M.Sc. at University of Plymouth, Plymouth, Great Britain and graduated in 1994 (M.Sc.) and 1998 (Ph.D.) in Chemistry at University of Ljubljana, Slovenia. She spent two years on postdoctoral studies at McGill University, Montreal, Canada. Upon her return to Jožef Stefan Institute, she set up a research group to study new emerging contaminants. Currently she is the Head of Laboratory for Organic Analytical Chemistry within the Department of Environmental Sciences, Jožef Stefan Institute and appointed Associate Professor in the Ecotechnology programme at the Jožef Stefan International Postgraduate School in Ljubljana, Slovenia. She is a member of the Division of Chemistry and the Environment (DCE) of the European Association for Chemistry and Molecular Sciences (EuCheMS) since 2012. Her main research interest is environmental organic chemistry and she has dedicated the last decade to the cycling and fate of new emerging contaminants during water treatment and in the environment.

Competences : environmental and analytical organic chemistry, persistent organic pollutants, new emerging contaminants, environmental and waste waters, sediment, soil, biological matrices, water treatment processes, bioremediation. 


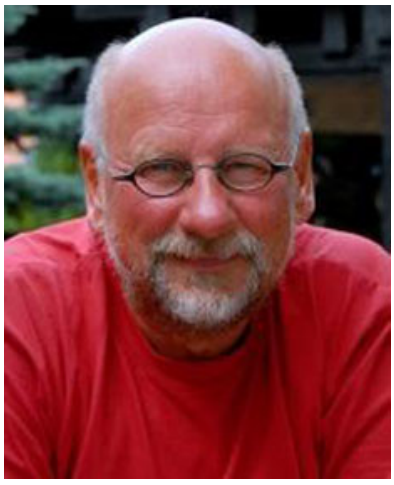

Dr. Leif Kronberg is professor of organic chemistry at Åbo Akademi University in Finland. He defended his doctoral thesis in 1987 and the following year he spent as "visiting scholar" at the University of North Carolina at Chapel Hill. In 1989, he went back to Åbo Akademi University and has since been working as researcher and teacher. His main research interests have been focused on the identification of chlorine disinfection products in drinking water, the study of reaction of highly reactive environmental pollutants with the base units of DNA, i.e. the formation of DNA adducts, and during the recent years, the fate and impact of pharmaceuticals residues in the aquatic environment

Competences : environmental organic chemistry, pharmaceuticals, endocrine disruptors, illicit drugs, genotoxins and mutagens, disinfection products, water, transformation reaction, disinfection, uptake and metabolism in biota, food genotoxins.

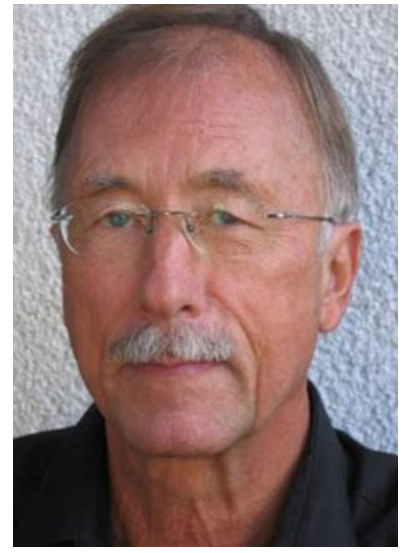

Dr. Michael Matthies is Full Professor for Applied Systems Analysis of the Department of Mathematics and Informatics at the University Osnabrueck. He has studied Physics in Muenster and Munich and obtained his $\mathrm{Ph}$. D. in Physical Chemistry in 1975 from the University Munich. He worked then two years as Research Assistant at the Institute of Biophysics, University Giessen. He joined in 1978 the newly established research group on $\mathrm{Ra}$ diation Risk Analysis of the German Centre of Radiation and Environmental Research in MunichNeuherberg, now Helmholtz Centre Munich, and in 1983 the Project Group on Hazard Assessment of Chemicals. He is the founder and first director of the interdisciplinary Institute of Environmental Systems Research. His main research interest is environmental modelling, exposure and risk assessment of organic pollutants in single and multimedia environments.

Competences : environmental modelling and risk assessment of organic pollutants, chemodynamic modelling, environmental exposure and risk assessment, organic pollutants, transport, degradation, persistence, bioaccumulation, long range transport potential (LRTP), georeferenced exposure assessment.

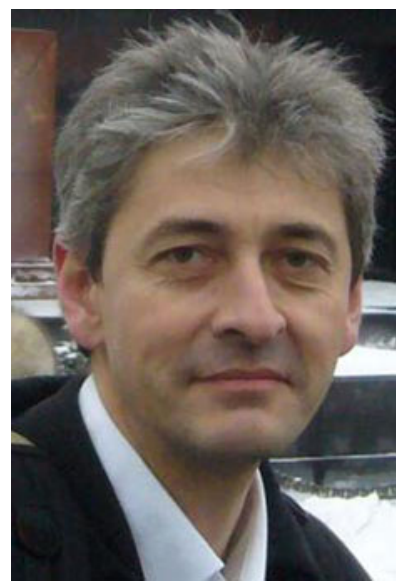

Dr. Gerhard Lammel is a full professor at the Masaryk University, Faculty of Science, Brno, Czech Republic and senior scientist at the Max Planck Institute for Chemistry, Mainz, Germany. He earned his $\mathrm{PhD}$ in Atmospheric Chemistry (1988) from the University of Mainz / Max Planck Institute for Chemistry and his teaching degree (Habilitation, 2000) for Environmental Chemistry from the University of Hohenheim, Stuttgart, Germany. In his research he has been focusing on aerosol chemistry through field and laboratory experimental studies and multicompartmental chemistry through modelling and field studies. He is a member of the Division on Chemistry and the Environment of EuCheMS (DCE, since 2004) and has been serving in various committees, the board of the Environmental Chemistry and Ecotoxicology branch of the German Chemical Society (GDCh, chair 2007-2010), besides other.

Competences : atmospheric chemistry, multicompartmental chemistry, aerosol science, modelling, field experiments, laboratory scale process studies, pesticides, heavy metal ions, global environmental change, sustainability.

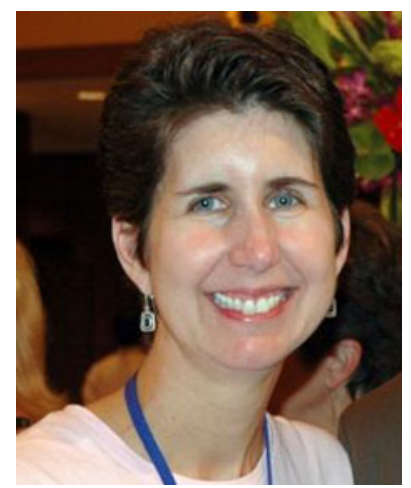

Dr. Laura McConnell is a research scientist at the US Department of Agriculture, Beltsville, Maryland. Her scientific background is in analytical and environmental chemistry, with a special focus on the investigation of the processes controlling the environmental fate and transport of pesticides, volatile organic compounds and other pollutants from agricultural operations. The ultimate goal of her research is to support the development of more sustainable farming systems that will minimize negative impacts on surrounding ecosystems. Dr. McConnell has received awards from within and outside her agency. She is currently the president of the International Union of Pure and Applied Chemistry (IUPAC), Division of Chemistry and the Environment, and she is active in the American Chemical Society (ACS) and the Society of Environmental Toxicology and Chemistry (SETAC).

Competences : analytical and environmental chemistry, pesticides, POPs, volatile organic compounds, brominated flame retardants, nutrients, odorants, air-water gas exchange of organic compounds, bioaccumulation and bioavailability of organic contaminants, regional and long-range atmospheric transport and deposition of organic contaminants, gas and particle emissions from agricultural operations, contaminants associated with biosolids and wastewaters. 


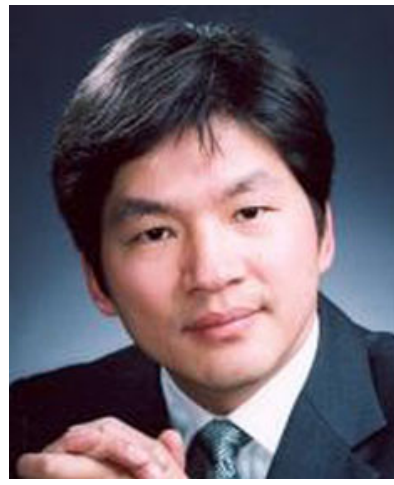

Dr. Bingcai Pan is a Full Professor of Department of Environmental Engineering, Nanjing University, and currently he serves as the department chair professor. He received his $\mathrm{PhD}$ degree of Environmental Engineering from Nanjing University (China). He has been employed in Nanjing University since 2003. Also, he serves as the deputy director of both State Key Laboratory of Pollution Control and Resource Reuse and National Engineering Centre for Organic Pollution Control and Resource Reuse (China). His work focused on environmental material-based water and wastewater treatment. In particular, he is interested in development of highly efficient nanocomposites and nanoporous materials for treatment and reuse of contaminated water.

Competences : environmental engineering, water and wastewater treatment, adsorption, ion exchange, oxidation/reduction, nanomaterials, heavy metals, organic chemicals, physicochemical processes, photo-induced industrial effluent, drinking water, groundwater.

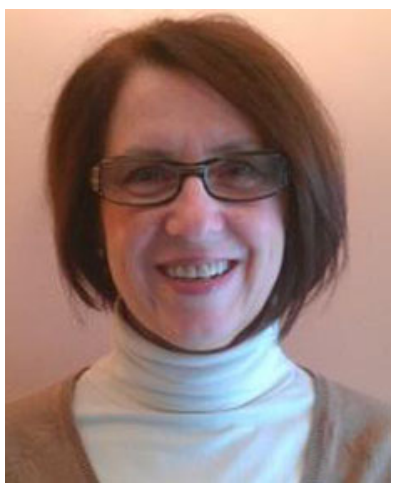

Dr. Constantini Samara is Professor of Environmental Chemistry in the Department of Chemistry, Aristotle University of Thessaloniki, Greece. She is Head of the Environmental Pollution Control Laboratory accredited to ISO 17025 for sampling and determination of aerosol in the ambient air. She coordinates the Thematic Network of the Aristotle University on «Integrated Research on Air Pollution, AIRnet». She has extensive involvement in air pollution studies with focus on particulate pollutants, such as heavy metals/toxic elements, toxic or carcinogenic organic compounds, and acidic ionic components. Also, she has developed research activity on the source identification/apportionment by employing receptor modeling. She is member of the advisory boards of Greek Environmental Agencies for air pollution.

Competences : air pollution analysis, source apportionment of ambient aerosol (receptor modeling), analytical organic chemistry, toxic organic compounds, acidic aerosol components, crustal elements, heavy metals, air/water exchange, wet/dry deposition.

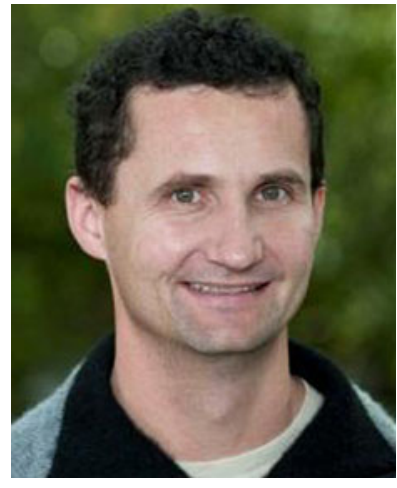

Dr. Stuart Simpson is a principal research scientist at CSIRO Land and Water, Sydney, Australia. His major research interest is sediment quality assessment, focussing on the quantification of the form (speciation), behaviour (bioavailability), ecotoxicological effects and the development of guidelines for regulating contaminants in sediments. His primary interest has been the analytical and environmental chemistry, reactivity, fate and processes controlling speciation, bioavailability and effects of metals in sediments.

Competences : environmental effects assessment (waters/sediment, freshwater/marine), sediment ecotoxicology, sediment quality assessment, metal speciation, metals, metalloids, bioavailability, speciation modelling, impacts of mining.

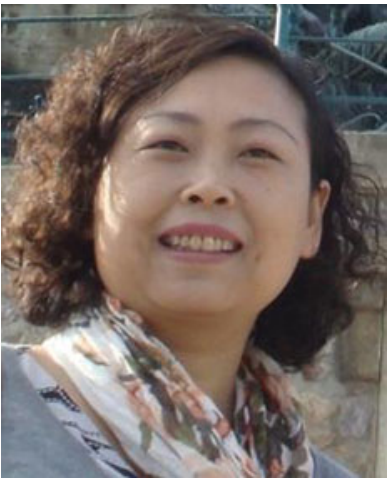

Dr. Hongwen Sun is a professor and deputy dean at College of Environmental Science and Engineering, Nankai University, China. She concurrently holds the post of executive vice director of Key Laboratory on Pollution Processes and Environmental Criteria (Nankai University) supported by Ministry of Education of China. She got her Ph. D. from Nankai University in 1994. She conducted postdoctoral research during 1999-2001 at Osaka University, Japan. She visited Swiss Federal Institute of Aquatic Science and Technology (Eawag), Switzerland as senior visiting scientist for three months in 2008. Her research interests are environmental chemistry of organic pollutants and remediation for polluted environment. She has coordinated over 25 research projects and participated in other 10 projects. She was honored as Excellent Young Fellow by Ministry of Education, China in 2004. She was elected as National Demonstrating Teacher in 2007. She won the Second Prize on Natural Science honored by Ministry of Education in 2010.

Competences : environmental chemistry, field monitoring, chemical experiments, organic pollutants (especially POPs and emerging organic chemicals), aquatic and terrestrial system, remediation of contaminated sites, human exposure of chemicals. 